Short communication

\title{
Chlamydia psittaci in fulmars on the Faroe Islands: a causative link to South American psittacines eight decades after a severe epidemic
}

\section{A R T I C L E I N F O}

\section{Article history:}

Received 15 October 2019

Accepted 21 February 2020

Available online 3 March 2020

\section{Keywords:}

Chlamydia psittaci

Fulmar

Psittacosis

Avian chlamydiosis

The Faroe Islands

\begin{abstract}
A B S T R A C T
A psittacosis epidemic linked to fulmar hunting occurred on the Faroe Islands in the 1930s. This study investigates a plausible explanation to the $20 \%$ human mortality in this outbreak. Phylogenetic analysis showed that Chlamydia psittaci isolated from fulmars were closely related to the highly virulent $6 \mathrm{BC}$ strains from psittacines and are compatible with an acquisition by fulmars of an ancestor of the 6BC clade in the 1930s. This supports the hypothesis that the outbreak on the Faroe Islands started after naïve fulmars acquired C. psittaci from infected dead parrots thrown overboard when shipped to Europe in the 1930s.
\end{abstract}

(c) 2020 The Authors. Published by Elsevier Masson SAS on behalf of Institut Pasteur. This is an open access article under the CC BY-NC-ND license (http://creativecommons.org/licenses/by-nc-nd/4.0/).
A psittacosis epidemic occurred in 1929-1930 and cases were mainly reported from the Americas and Europe, with a case fatality rate of $15 \%$ [1]. The principal source of infections is assumed to be infected parrots from South America [1]. On the Faroe Islands (Fig. 1), 174 cases of psittacosis were reported between 1930 and 1938. Locals got infected when juvenile fulmars (Fulmarus glacialis) were caught and prepared for cooking [2]. Fatality rate averaged $20 \%$, but reached $80 \%$ in pregnant women.

In fulmars collected on the Faroe Islands in 1999, the prevalence of Chlamydia psittaci was $10 \%$. It was hypothesized that fulmars contracted C. psittaci from infected parrots shipped from South America to Europe and thrown overboard when they died during the transport in the 1930s [3]. The present study aimed to test this hypothesis by attempting to isolate $C$. psittaci strains from fulmars on the Faroe Islands and characterize isolates by whole genome sequencing to enable comparison with other representative strains.

\footnotetext{
* Corresponding author. Department of Clinical Microbiology, Uppsala University Hospital, SE-751 85 Uppsala, Sweden. Fax: +46 18559157.

E-mail address: bjorn.herrmann@medsci.uu.se (B. Herrmann).
}

\section{Material and methods}

\subsection{Ethics}

According to the Faroese 'Bird Game Act' (Løgtingslóg nr. 27 frá 9. september 1954 um fuglaveiðu v.m., sum seinast broytt við løgtingslóg nr. 48 frá 15. mai 2014), the Northern Fulmar F. glacialis can be hunted (using legal hunting techniques) on land and sea all year around in the Faroe Islands. As such, it is legal to catch and kill both adults and recently fledged juveniles for consumption.

\subsection{Collection of samples, detection and culture of $\mathrm{C}$. psittaci}

Non-flying juvenile fulmars were caught for cooking on the sea around the Faroe Islands in August 2016. Duplicate cloacal swab samples for PCR and culture were stored in sucrose phosphatebuffered glutamate (SPG) solution on dry ice and transported to Sweden for analysis. DNA was extracted using the PowerSoil DNA Isolation Kit (MO BIO Laboratories, Carlsbad, CA, USA) and screening for Chlamydiaceae was performed by a 23S rRNA-gene based PCR [4] and confirmed as C. psittaci by a specific PCR assay [5]. 


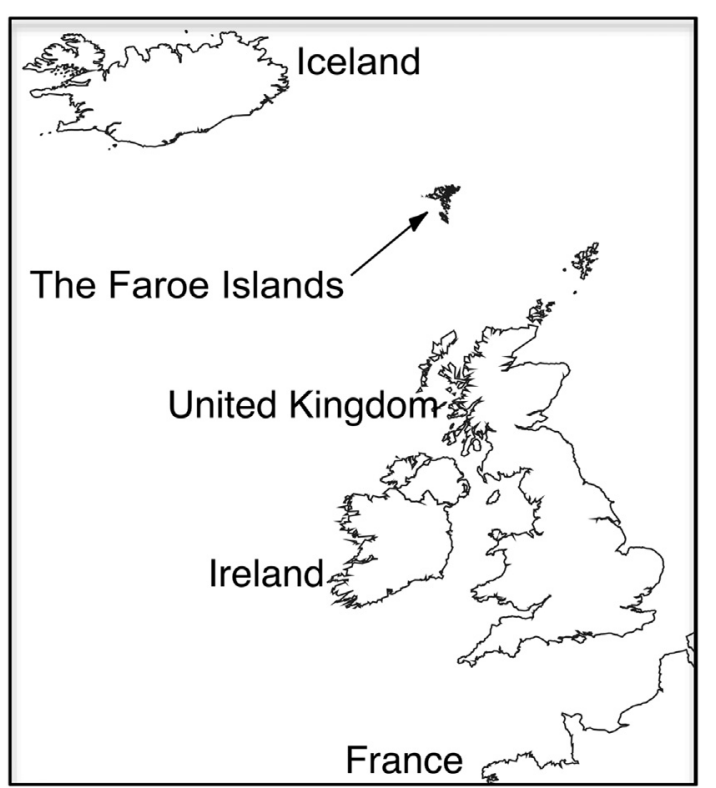

Fig. 1. Map of the northern Atlantic showing the Faroe Islands and surrounding areas. Source: Faroese Museum of Natural History. Adapted by Janus Hansen.

PCR positive samples were cultivated in Buffalo Green Monkey Kidney cells (BGMK) using Minimum Essential Medium Eagle supplemented with $5 \%$ fetal bovine serum and $2 \mathrm{mM}$ L-glutamine. Monolayers were infected with $200 \mu \mathrm{L}$ of the swab SPG and centrifuged at $2000 \mathrm{~g}$ during $1 \mathrm{~h}$. Cells were incubated at $37{ }^{\circ} \mathrm{C}$ in MDCK medium and stained $48 \mathrm{~h}$ post infection with an immunofluorescent test (Imagen Chlamydia IF, Oxoid). Positive monolayers were harvested in SPG buffer and kept at $-80^{\circ} \mathrm{C}$. All experiments involving cultivation of $C$. psittaci cells were conducted in a Biosafety Level 3 facility.

\subsection{Gene sequencing}

Genomic DNA was extracted with the Qiamp DNA minikit (Qiagen) and tested with a multilocus sequence typing (MLST) scheme designed for $C$. psittaci [6]. Multiple alignments of the seven concatenated MLST gene fragments were conducted using Mega6 software and a dendrogram was constructed using NJ. For dendrogram construction, sequences were trimmed to $3098 \mathrm{bp}$.

DNA libraries were prepared using the Nextera XT kit (Illumina). Whole-genome shotgun sequencing of the $C$. psittaci isolate was performed using an Illumina MiSeq platform (Illumina) according to the manufacturer's instructions. The MiSeq run was carried out on the DNA preparation, with paired-end reads of $150 \mathrm{bp}$ using MiSeq V2 reagents. Raw reads were trimmed and assembled de novo using SPAdes 3.13.1 [7]. Contigs from SPAdes were subsequently blasted on the nucleotide database of NCBI to remove residual mammalian sequences from cell culture constituents. Raw sequences contained $\sim 15 \%$ of reads from mammalian DNA. Three of the assembled contigs had a coverage over $100 \times$ and contained C. psittaci DNA: two contigs (862 433 and $308884 \mathrm{nt}$ ) forming the chromosome and one plasmid (7553 nt). Average coverage was $190 \times$ for the two contigs and $2000 \times$ for the plasmid. The respective orientation of the two chromosomal contigs was confirmed with PCR reactions in each possible combination (see primer sequences in Supplementary Table 1 in Appendix A). The two resulting PCR products were sequenced with Sanger sequencing and the chromosome was closed using these sequences.
Mapping of reads to the reference genome 6BC (CP002549) were performed using CLC Genomics Workbench 11.0.1. The Ful127 scaffolded genome and reference genome were compared using Mauve whole genome alignment to identify conserved and rearranged regions. The average nucleotide identity (ANI) was calculated according to Ref. [8] on the website http://enve-omics.ce. gatech.edu/ani/.

\subsection{Phylogenetics}

In short, 65 complete $C$. psittaci genomes retrieved from NCBI and the newly sequenced genome of $C$. psittaci Ful 127 were aligned using progressiveMauve [9]. After quality inspection, 11 genomes were removed and the remaining 55 genomes were re-aligned similarly. Out of the 1044 segments aligned by progressiveMauve (total length of $2.17 \mathrm{Mb}$ ), those present in all 55 genomes (core genome of $1.25 \mathrm{Mb}$ ) were concatenated and trimmed of any position containing any gap. The resulting gapless alignment $(1.04 \mathrm{Mb})$ was used to infer a phylogenomic tree. A detailed description is given in Appendix A.

\subsection{Data availability}

Sequence data of the Ful127 isolate are available at NCBI under BioProject accession PRJNA490061. MLST profile is accessible via the Chlamydiales MLST website under id 4026 (http://pubmlst.org/ chlamydiales/http://mlst.ucc.ie/). See also data in Appendix Supplementary Information.

\section{Results}

Chlamydiaceae DNA was detected in two of 474 birds ( $0.4 \%)$, and confirmed as $C$. psittaci by the specific PCR assay. One isolate could be propagated onto BGM cells from the Fulmar sample 127 (hereafter referred to as Ful127). Genome sequencing of Ful127 resulted in a single, circular, $1.171-\mathrm{Mb}$ chromosome (accession number CP033059) and a circular 7.5-kb plasmid (accession number CP033060).

The obtained phylogenetic tree generated by multilocus sequence typing (MLST) and based on all available C. psittaci sequence types (STs) reveals that Ful127 belongs to a new sequence type (ST197), with close relation with the sequence type ST24, mostly isolated from psittacine birds (Fig. 2A). The only differences between ST197 and ST24 were two substitutions in the hflX gene, while the other six genes were identical.

A comparison between Ful127 and genomes from the 6BC clade, i.e. strains from psittacines, reveals that both strain types are very similar. The average nucleotide identity was $99.38 \%$ between the two chromosomes, and $99.99 \%$ between the two plasmids. Phylogenetic analysis of the Ful127 and 54 other C. psittaci complete chromosomes resulted in a tree slightly different to the MLST tree (Fig. 2B). Here, Ful127 is equally close to the 6BC clade and to the VS225 strain, which also has a psittacine host.

\section{Discussion}

The $C$. psittaci prevalence in fulmars was unexpectedly low in 2016 compared to our previous study in 1999, but similar to the findings in most studies of wild birds [10-12]. This might reflect the decreasing number of reported psittacosis cases on the Faroe Islands: for the period $1954-2003$ it was 2.2 per 100000 inhabitants and year [3], while it fell to 0.3 per 100000 inhabitants and year for 2004-2016 (Shahin Gaini, personal communication). The decrease in zoonotic infections is partly attributed to improved hygiene during the preparation process, including bird catching, 
a

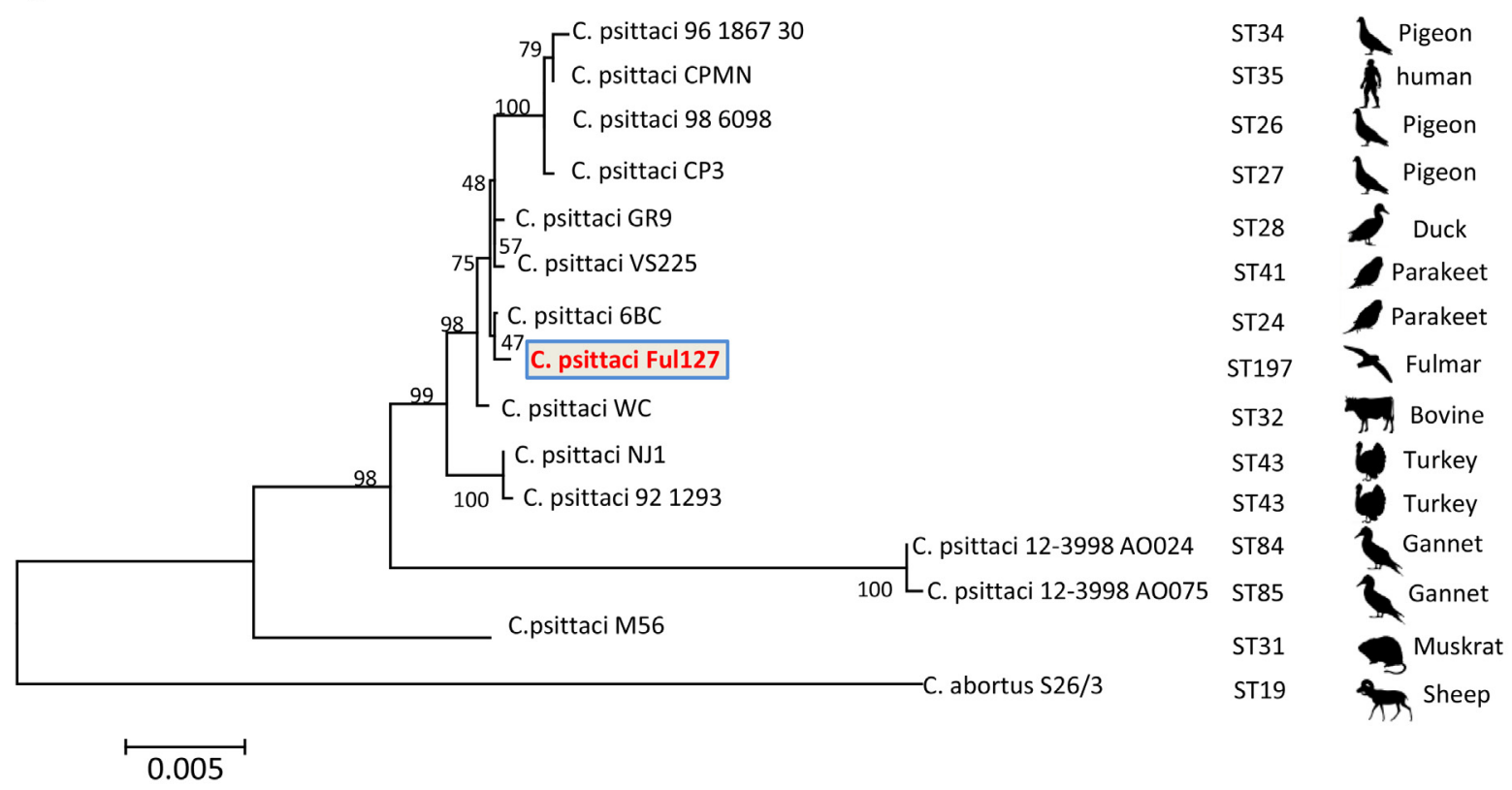

b

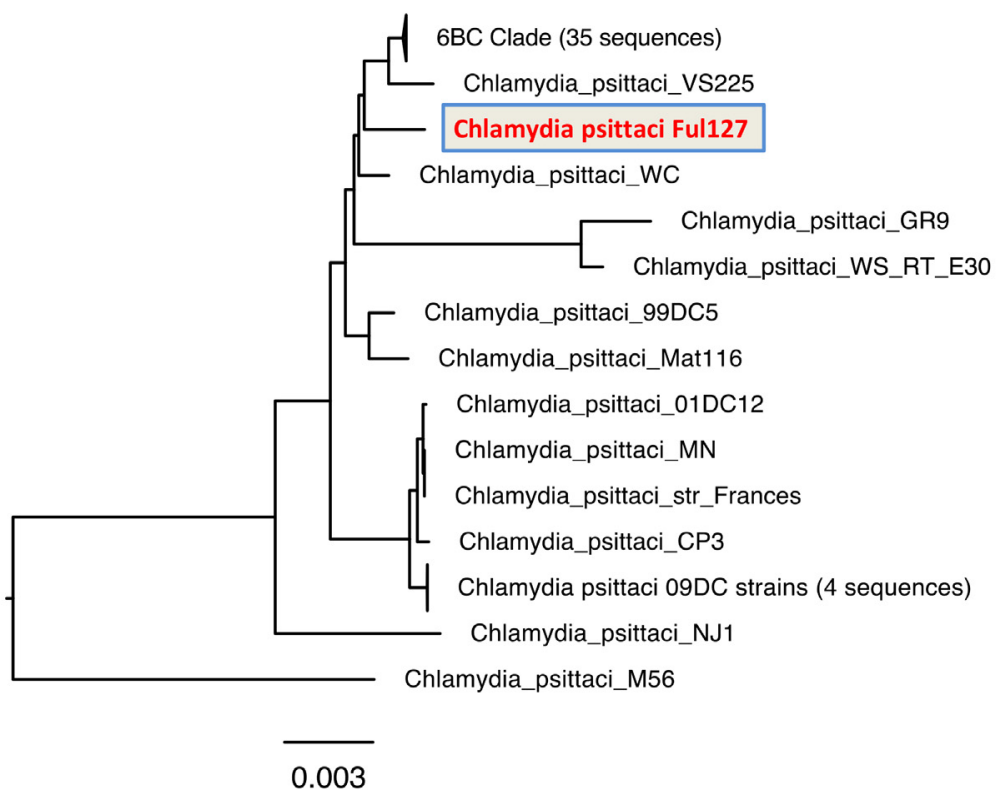

MLST ST Host

\begin{tabular}{|c|c|}
\hline ST24 & Multiple hosts \\
\hline ST41 & arakeet \\
\hline ST197 & Fulmar \\
\hline ST32 & Bovine \\
\hline ST28 & Duck \\
\hline ST28 & Duck \\
\hline Novel & Horse \\
\hline Novel & Avian \\
\hline ST56 & Pig \\
\hline ST35 & Human \\
\hline ST35 & Ferret \\
\hline ST27 & Pigeon \\
\hline ST47 & Pigeon \\
\hline ST43 & Turkey \\
\hline ST31 & Muskrat \\
\hline
\end{tabular}

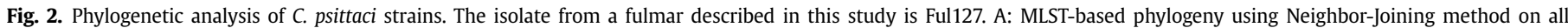

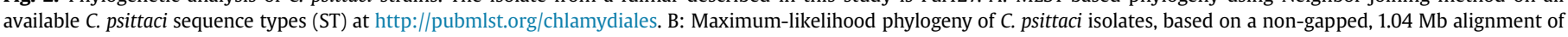

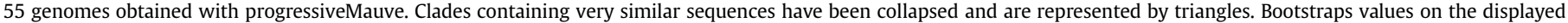
branches are all 100 . The scale represents the number of substitutions per site. For comparison, STs as determined by MLST are shown.

feather-plucking and meat handling. Considering that up to 80000 fulmars are caught each year (i.e. approximately 1.6 bird/inhabitant/year), with close contact to humans, we can conclude that the risk of psittacosis from such wild birds in general is lower today. At the same time there is also an under-diagnosis of psittacosis, which recently was reported by national figures in 2017 and a recent study [13].

The major outer membrane protein gene ompA is a hot-spot for mutations and is commonly used for genotyping chlamydia, including genotypes described for $C$. psittaci [14,15]. The ompA sequence in the fulmar isolate Ful127 was strictly identical to 29 sequences obtained from fulmars on the Faroe Islands in our previous study [3], strongly indicating that Ful127 is a direct offspring from the strains prevailing on the Faroe Islands 17 years earlier. Further, the ompA sequence from Ful127 differed in one position compared to the 6BC C. psittaci sequence. Only scarce MLST data are available from $C$. psittaci-positive samples obtained from seabirds, but the reported sequence types from northern gannets (Morus 
bassanus) (ST84 and ST85) [16] are distant from Ful127. The almost identical ompA and MLST gene sequences in Ful127 and strains that belong to the $6 \mathrm{BC}$ clade indicate a close relatedness between those two clades.

From one study by Branley and coworkers, it is possible to estimate the divergence of the Ful127 isolate with the VS225/6BC group to have occurred between 4000 and 2000 years ago (divergence VS225 and the 6BC clade: 2000 years ago; divergence of WC and the VS225/6BC clade: 4000 years ago) [17]. From another study by Read et al., the divergence of the Ful127 with the VS225/6BC group can be estimated to occur shortly after 1916 or 1930 , depending of the method used [18]. In the absence of other calibrating points, estimating divergence times is highly dependent on calculations of substitution rates, which, in turn, is dependent on sequence alignments used.

Although we cannot fully discard the result by Branley et al., three lines of evidence favor the placement of the divergence of Ful127 from the ancestor of the 6BC group in the early 20th century: (i) Branley et al. based their analysis on a conservative, $172 \mathrm{~kb}$-long alignment, which is likely to contain only the most conserved regions, while Read et al. used a 6-fold larger alignment (about 1.1 Mb); (ii) Branley et al. assumed a strict molecular clock in their estimation of the divergence times, whereas Read et al. chose a more realistic relaxed clock; (iii) the two independent estimations provided by Read et al. yield strikingly similar results. In particular, the choice of a strict molecular clock assumes that the substitution rates are constant throughout the tree. Such an assumption should be tested [19], especially in intracellular bacteria, where the smaller population sizes often correlate with a loss of DNA enzymes, leading to drastic changes in mutation rates $[20,21]$, and thus invalidating the use of a strict molecular clock.

The substitution rates found for the study by Read et al. are high $\left(1.74 \times 10^{-5}\right.$ substitutions per year and site with the method that discard recombining regions) but compatible with rates found in other bacteria. For example, a rate of $2.5 \times 10^{-5}$ per site and year has been inferred from whole-genome alignments of Helicobacter pylori [22], and a study encompassing 16 species found that substitution rates span 3 orders of magnitude, from $10^{-8}$ to $10^{-5}[23]$.

In the light of this, we consider that the placement of Ful127 on the tree is compatible with an acquisition of a strain of the ancestor of the 6BC clade to fulmars in the 1930s and thereafter divergence to a separate branch.

The Ful127 isolate has only minor genetic differences compared to the $6 \mathrm{BC}$ clade and VS225 which indicates a recent emergence of this lineage. Overall the data presented support for the hypothesis that $C$. psittaci strains of the 6BC clade were transmitted to fulmars feeding infected and dead parrots thrown overboard during shipment from Argentina to Europe in the 1930s. Early works based on epidemiological data from both human and avian psittacosis also support this hypothesis [24,25]. Because the fulmars were naïve to these strains, they likely developed symptomatic disease which contributed to the psittacosis cases in humans. This hypothesis is also supported by reports that strains from the 6BC clade are highly virulent $[17,18]$. We suggest that ongoing adaptation of the $6 \mathrm{BC}$ like strains to the fulmar as host in combination with improved hygiene has resulted in psittacosis rates on the Faroe Islands similar to what is reported from most other countries.

\section{Declaration of competing interest}

All authors declare they have no conflict of interest.

\section{Acknowledgments}

We thank Janus Hansen for providing the map of Fig. 1. The investigation was funded by the Department of Clinical Microbiology at the Uppsala University Hospital, Sweden.

\section{Appendix A. Supplementary data}

Supplementary data to this article can be found online at https://doi.org/10.1016/j.micinf.2020.02.007.

\section{References}

[1] Pospischil A. From disease to etiology: historical aspects of Chlamydia-related diseases in animals and humans. Drugs Today 2009;45(Suppl B):141-6.

[2] Rasmussen-Ejde R. Ueber eine durch Sturmvögel übertragbare Lungenerkrankung auf den Färöern. Zentralbl Bakteriol Parasitenkunde Infektionskrankheiten 1938;143:89-93. Erste Abteilung Originale.

[3] Herrmann B, Persson H, Jensen JK, Joensen HD, Klint M, Olsen B. Chlamydophila psittaci in fulmars, the Faroe Islands. Emerg Infect Dis 2006;12:330-2.

[4] Ehricht R, Slickers P, Goellner S, Hotzel H, Sachse K. Optimized DNA microarray assay allows detection and genotyping of single PCR-amplifiable target copies. Mol Cell Probes 2006;20:60-3.

[5] Heddema ER, Beld MG, de Wever B, Langerak AA, Pannekoek Y, Duim B. Development of an internally controlled real-time PCR assay for detection of Chlamydophila psittaci in the LightCycler 2.0 system. Clin Microbiol Infect 2006; 12:571-5.

[6] Pannekoek Y, Dickx V, Beeckman DS, Jolley KA, Keijzers WC, Vretou E, et al. Multi locus sequence typing of Chlamydia reveals an association between Chlamydia psittaci genotypes and host species. PLoS One 2010;5:e14179.

[7] Bankevich A, Nurk S, Antipov D, Gurevich AA, Dvorkin M, Kulikov AS, et al. SPAdes: a new genome assembly algorithm and its applications to single-cell sequencing. J Comput Biol 2012;19:455-77.

[8] Goris J, Konstantinidis KT, Klappenbach JA, Coenye T, Vandamme P, Tiedje JM, et al. DNA-DNA hybridization values and their relationship to whole-genome sequence similarities. Int J Syst Evol Microbiol 2007;57:81-91.

[9] Darling AE, Mau B, Perna NT. ProgressiveMauve: multiple genome alignment with gene gain, loss and rearrangement. PLoS One 2010;5:e11147.

[10] McElnea CL, Cross GM. Methods of detection of Chlamydia psittaci in domesticated and wild birds. Aust Vet J 1999;77:516-21.

[11] Blomqvist M, Christerson L, Waldenström J, Lindberg P, Helander B, Gunnarsson G, et al. Chlamydia psittaci in birds of prey, Sweden. Infect Ecol Epidemiol 2012;2.

[12] Jeong J, An I, Oem JK, Wang SJ, Kim Y, Shin JH, et al. Molecular prevalence and genotyping of Chlamydia spp. in wild birds from South Korea. J Vet Med Sci 2017;79:1204-9.

[13] Fossadal ME, Grand M, Gaini S. Chlamydophila psittaci pneumonia associated to exposure to fulmar birds (Fulmaris glacialis) in the Faroe Islands. Infect Dis 2018:50:817-21.

[14] Heddema ER, van Hannen EJ, Duim B, Vandenbroucke-Grauls CM, Pannekoek Y. Genotyping of Chlamydophila psittaci in human samples. Emerg Infect Dis 2006;12:1989-90.

[15] Knittler MR, Sachse K. Chlamydia psittaci: update on an underestimated zoonotic agent. Pathog Dis 2015;73:1-15.

[16] Aaziz R, Gourlay P, Vorimore F, Sachse K, Siarkou VI, Laroucau K, et al. Chlamydiaceae in North Atlantic seabirds admitted to a wildlife rescue center in western France. Appl Environ Microbiol 2015;81:4581-90.

[17] Branley J, Bachmann NL, Jelocnik M, Myers GS, Polkinghorne A. Australian human and parrot Chlamydia psittaci strains cluster within the highly virulent 6BC clade of this important zoonotic pathogen. Sci Rep 2016:6:30019.

[18] Read TD, Joseph SJ, Didelot X, Liang B, Patel L, Dean D, et al. Comparative analysis of Chlamydia psittaci genomes reveals the recent emergence of a pathogenic lineage with a broad host range. mBio 2013;4:e00604-12.

[19] Drummond AJ, Ho SY, Phillips MJ, Rambaut A. Relaxed phylogenetics and dating with confidence. PLoS Biol 2006;4:e88.

[20] Toft C, Andersson SG. Evolutionary microbial genomics: insights into bacterial host adaptation. Nat Rev Genet 2010;11:465-75.

[21] Wernegreen JJ. Endosymbiont evolution: predictions from theory and surprises from genomes. Ann N Y Acad Sci 2015;1360:16-35.

[22] Kennemann L, Didelot X, Aebischer T, Kuhn S, Drescher B, Droege M, et al. Helicobacter pylori genome evolution during human infection. Proc Natl Acad Sci U S A 2011;108:5033-8.

[23] Duchêne S, Holt KE, Weill FX, Le Hello S, Hawkey J, Edwards DJ, et al. Genomescale rates of evolutionary change in bacteria. Microb Genom 2016;30(2): e000094.

[24] Sturdee EL, Scott WM. A disease of parrots communicable to man (Psittacosis). Public Health and Medical Subjects No. 61. London: Ministry of Health; 1930. p. $1-133$.

[25] Miles JAR, Shrivastav JB. Ornithosis in certain sea-birds. J Anim Ecol 1951;20: 195-200. 